\title{
Evaluation of the Utilization of Electric Vehicles for Building Energy Management in Hotels
}

\author{
Carlos Gamallo, Roberto Álvaro, Jesús Fraile-Ardanuy \\ Jairo González
}

\author{
Manuel Fuentes
}

\begin{abstract}
Governments are working in new policies to slow down total energy consumption and greenhouse gases (GHG) emissions, promoting the deployment of electric vehicles (EVs) in all countries. In order to facilitate this deployment and help to reduce the final costs of their batteries, additional utilization of EVs when those are parked has been proposed. EVs can be used to minimize the total electricity cost of buildings (named vehicle to building applications, V2B).
\end{abstract}

In this paper an economic evaluation of EVs in the Building Energy Management System is shown. The optimal storage capacity and its equivalent number of EVs are determined. This value is then used for determining the optimal charging schedule to be applied to the batteries. From this schedule, the total expected profit is derived for the case of a real hotel in Spain.

Keywords-electric vehicles; vehicle to building; optimization; battery storage.

\section{INTRODUCTION}

One of the biggest concerns in all countries is the reduction of fossil fuels consumption, reducing their external energy dependence and economic vulnerability and contributing to decrease $\mathrm{CO}_{2}$ and other greenhouse gas (GHG) emissions that are warming our planet [1].

Global transportation sector is one of the main producers of GHG in the world (26.5\% in the European Union [2-4] and in $28 \%$ in the US [5]), therefore governments are promoting different initiatives to boost the transition from conventional internal combustion engine (ICE) vehicles to plug-in hybrid electric vehicles (PHEV) or battery electric vehicles (BEV) [6]. This transition will allow transportation sustainability, environmental benefit, improved social welfare, employment creation and economic growth.

Residential and commercial buildings are responsible for $40 \%$ of total final world's energy consumption [7] and an important part of global GHG emissions. The building sector offers the largest low-cost potential of GHG emissions reduction in all world regions [8]. In this case, governments are promoting the deployment of distributed renewable generation in buildings and energy efficiency polices [9].

Hotels are in the top five of the total energy consumption in the tertiary building sector [10]. This energy cost represents about 6-7 percent of all hotel operating costs [10-12], therefore the application of energy efficiency actions could produce a direct profit increase.

Travel and tourism sector in Spain is one of the main contributors to the Spanish GDP, reaching $15 \%$ of the total GDP contribution and supporting 488,500 directly jobs and $2,304,500$ indirectly jobs [13]. These figures are even bigger in the case of the two Spanish archipelagos (Canary Islands and Balearic Islands). For example, the impact of this sector to the GDP in Canary Islands reaches almost 30\%, supporting 262,823 jobs (34.2\% of the total employment) [14].

Most of the total energy demand in these archipelagos comes from imported fossil fuels, having a negative impact in its economy and its environment. These areas are considered as an ideal location to introduce electric vehicles because the small size of the different islands limits the driving, reducing the driver's range anxiety and allowing a cleaner environment.

Usually, EV-PHEVs are seen as loads attached to buildings during the charging periods, increasing the total buildings' electric demand. Significant research has been done analysing the impact of this charging on the building electric grid or on the distribution grid, depending on the charging strategy [15$18]$.

On the other hand, batteries from EV-PHEVs can be combined with the Building Energy Management Systems (BEMS), storing energy when the electricity price is low and feeding back to the building when the electricity price is high, reducing the total building's electric energy cost.

This combination produces an economic benefit not only for the building operators, but also for the car owners, since they receive a variable payment for the energy storage capacity and exchange with their batteries. 
Similar concepts have been proposed in the literature. In [19] an EV was integrated with the energy management system of a single house, allowing a reduction of the peak power demand from the electric grid and an increase of the load factor.

The integration of PHEVs into a northern California office building was presented in [20]. In this case, different business models were proposed to share the overall benefit among the building owner and the vehicle owners. These authors have also proposed to integrate on-site micro generation in the building, optimizing the annual building energy costs and the $\mathrm{CO}_{2}$ emissions [21]. In [22] additional benefits are obtained, providing microgrid's power supply and offering frequency regulation to the system operator.

The objectives of this paper are firstly to determine optimal storage capacity needed to reduce the hotel total electricity cost during one year (other optimization criteria could be easily implemented), assuming different payments for EV owners. The second objective is to evaluate how to distribute this capacity among the batteries of several vehicles parked at the hotel and arriving with different initial State of Charge (SOC) at the time of connection and determine an optimal chargingdischarging schedule for one day. To simplify the problem, it is assumed that all EVs belong to the hotel (i.e. a leasing agreement) and there are always a minimum number of connected EVs all the time.

The remaining of this paper is organized as follows: in Section II the energy management system (EMS) is presented. The evaluation of the optimal needed capacity is provided in Section III. Section IV shows the schedule of a daily program, taking into account the capacity sharing among several EVs. Results and conclusion are finally drawn in the last section.

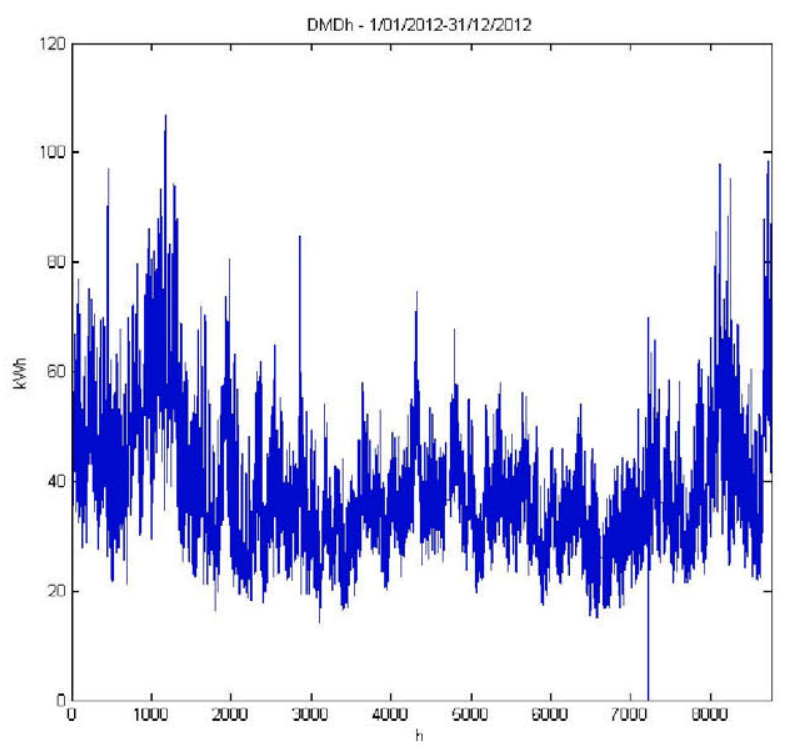

Fig. 1. 2012 hotel annual hourly global demand

\section{SYSTEM MODELING}

The building consumption data was extracted from a real hotel located in a tourism city in Spain. This building currently has multiple sensors that monitor different parameters of its energy consumption (voltage, current, active and reactive power, power factor, etc.) for different lines. In this work, the total electricity aggregated consumption is used as input for the model. Fig. 1 presents the annual hourly global demand during year 2012 .

The building has an electricity supply contract with the utility company composed of three components [23]: a fixed active power-depending term $(€ / \mathrm{kW})$ representing the capacity charge, an energy-depending term $(€ / \mathrm{kWh})$ which is a function of the energy consumed by the building and the reactive energy charge ( $€ / \mathrm{kVArh})$, depending on the total power factor $(\mathrm{PF})$.

An automatic PF correction system is used to maintain a desired target PF above 0.95 on the low voltage distribution system of the hotel facility, therefore there is no penalty for reactive power consumption. The energy term in the tariff bill is a linear function that multiplies a coefficient depending on the period of the day and the amount of energy consumed during that period. The prices and periods used in this work are presented in Fig. 2.

Fig. 3 shows the energy flows considered in the model, based on [20]. In this figure the charge/discharge decisions depend on the instantaneous energy price offered by the market, the state of the system and the value of exogenous variables such as the actual building energy demand. The existence of an entity called EMS (Energy Management System) or aggregator is assumed. This entity is an abstraction of all the control logic, electrical and data networks, and all the needed electrical systems that allows the building to take appropriate consumption decisions at all times. Table I describes the different variables and parameters (with their nominal values) considered in the system. The variables for the optimization have their values in blank.

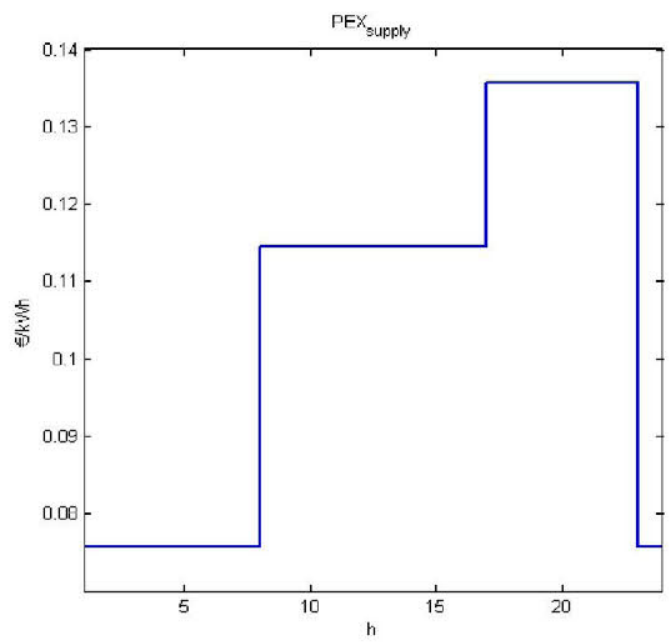

Fig. 2. Hourly electricity price 


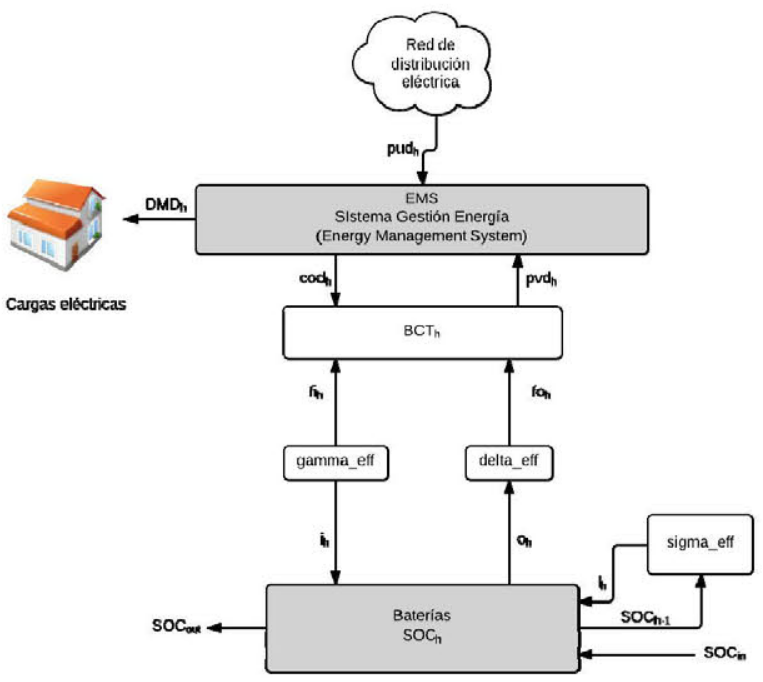

Fig. 3. Energy flow model for BEV storage-EMS

In each time period, the EMS takes charging or discharging decisions according to the system state variables. The system could even sell power to the grid in order to provide regulatory services as presented in [22], although the modelling of this possibility is beyond the scope of this work. The EMS will likely storage the energy when prices reach their lowest level and sell it when they reach their highest one.

The presence/absence of EVs parked (and connected) in the hotel has been modelled using the block named BCT (a 1 and 0 vector) that simulates the connection / disconnection of the batteries the EMS system. From the perspective of the building, the presence of EVs available for electric power storage is equivalent to the presence of static battery blocks devoted for the same purpose, with the exception that its availability is variable in time.

From the hotel perspective, there are three main costs to be minimized:

- The total energy bought to the grid.

- The battery acquisition cost.

- The reward paid to the car owners that plug their car in the system and allow extra charge and discharge cycles for the hotel energy consumption optimization. This price may be interpreted as a degradation cost in case the cars belong to the hotel or compensation if the system were to be offered to the clients.

\section{OPTIMAL STORAGE CAPACITY EVALUATION}

Taking a year as the optimization window, the business model described would be formalized as follows:

$$
\begin{gathered}
\min \sum_{h}\left(p u d(h) \cdot P E X_{\text {supply }}(h)\right. \\
\left.+(f o(h)-f i(h)) P E X_{E V}(h)\right)+(F+V \cdot C)
\end{gathered}
$$

Subject to the following restrictions:

$$
S O C_{\min } \leq S O C(h) \leq S O C_{\max }
$$

$$
\begin{gathered}
0 \leq i(h) \leq C \cdot D R \\
0 \leq o(h) \leq C \cdot D R \\
S O C(h)=S O C(h-1)+i(h)-o(h)-l(h) \\
l(h)=S O C(h-1) \cdot \Phi_{\text {decay }} \\
f o(h)=o(h) \cdot \delta_{\text {eff }} \\
i(h)=f i(h) \cdot \gamma_{e f f} \\
\operatorname{cod}(h)=B C T(h) \cdot f i(h) \\
p v d(h)=B C T(h) \cdot f o(h) \\
\operatorname{pud}(h)=D M D(h)+c o d(h)-p v d(h) \\
\text { SOC }(h), \operatorname{pud}(h), c o d(h), p v d(h), f i(h), f o(h), \\
i(h), o(h) \geq 0
\end{gathered}
$$

\begin{tabular}{|c|c|c|c|}
\hline Description & Symbol & Value & Unit \\
\hline Building Energy Demand & $\mathrm{DMD}_{\mathrm{h}}$ & {$\left[\mathrm{DMD}_{\mathrm{h}}\right]$} & $\mathrm{kWh}$ \\
\hline Energy hourly Price & $\mathrm{PEX}_{\text {supply }}$ & {$\left[\mathrm{PEX}_{\mathrm{h}}\right]$} & $\epsilon / \mathrm{kWh}$ \\
\hline Battery capacity & $\mathrm{C}$ & & $\mathrm{kWh}$ \\
\hline System Energy Demand & pud & & $\mathrm{kWh}$ \\
\hline Available Charge Energy & $\operatorname{cod}$ & & $\mathrm{kWh}$ \\
\hline Available Discharge Energy & pvd & & $\mathrm{kWh}$ \\
\hline Charge input & fi & & $\mathrm{kWh}$ \\
\hline Discharge input & fo & & $\mathrm{kWh}$ \\
\hline Discharge energy & i & & $\mathrm{kWh}$ \\
\hline Charge energy & o & & $\mathrm{kWh}$ \\
\hline Self-discharge energy & 1 & & $\mathrm{kWh}$ \\
\hline Battery block fixed cost & $\mathrm{F}$ & 100 & $€$ \\
\hline Battery block variable cost & $\mathrm{V}$ & 150 & $\epsilon / \mathrm{kWh}$ \\
\hline Maximum Discharge Rate & DR & 0,1 & - \\
\hline Minimum Charge Rate & $\mathrm{CR}$ & 0,1 & - \\
\hline Charge efficiency rate & $\gamma_{\text {eff }}$ & 0,95 & - \\
\hline Discharge efficiency rate & $\delta_{\text {eff }}$ & 0,95 & - \\
\hline Self-discharge rate & $\Phi_{\mathrm{eff}}$ & $1,6 \cdot \mathrm{E}-05$ & - \\
\hline Minimum allowed SOC & $\mathrm{SOC}_{\min }$ & 20 & $\%$ \\
\hline Maximum allowed SOC & $\mathrm{SOC}_{\max }$ & 95 & $\%$ \\
\hline Initial SOC & $\mathrm{SOC}(0)$ & 20 & $\%$ \\
\hline Conn./Discon. Matrix & {$\left[\mathrm{BCT}_{\mathrm{h}}\right]$} & $\{0,1\}$ & - \\
\hline
\end{tabular}

TABLE I. OPTIMIZATION MODEL VARIABLES AND PARAMETERS 


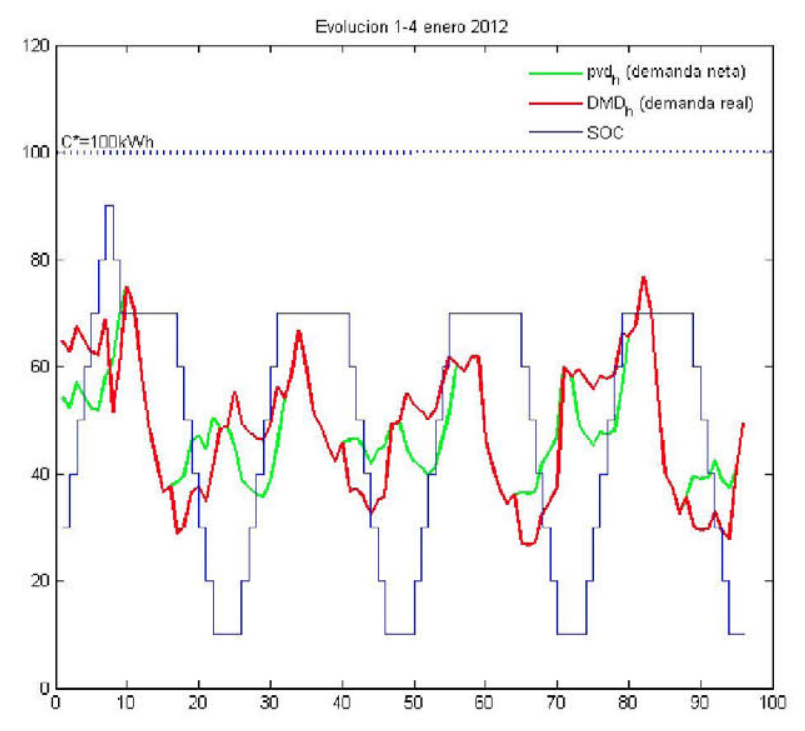

Fig. 4. Evolution of total SOC, building demand and real power demand extracted from the grid.

The objective function (1) minimizes the total cost of the system. The first term is the price paid to the utility company for the energy consumption; the second term, a price relative to the usage of the battery (battery usage compensation and/or degradation) and the third term, the fixed and variable costs of the installation.

Constraints (2), (3) and (4) set the limit for battery SOC, charging and discharging. Constraint (5) describes the SOC evolution due to charging, discharging and self-discharging (6). Efficiency has to be considered for battery charging and discharging (7-8), as well as vehicle's availability (9-10). Building consumption is then considered in constraint (11). Finally, the positive definition of variables guaranties that the total consumption of the hotel is higher than 0 , preventing inefficiency economies.

GAMS ${ }^{\circledR}$ and Cplex Solver optimizer have been used for the resolution of the problem. Due to the large number of existing

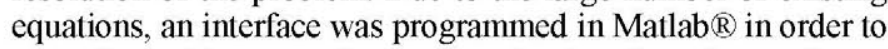
write the problem equations and read and analyse the results.

\section{DAILY PROGRAM AND SHARING CAPACITY}

Once the optimal capacity has been calculated, an hourly operation program shall be scheduled for every day. Here, it must be considered that there is not a single battery, but a number of vehicles in which the calculated capacity is shared. The program is based on the optimization of the previous problem considering that now each vehicle parks in the building with a different SOC and should leave with the same amount of energy they entered with. This algorithm can also be used if a higher SOC would be required at departure time, since the client's energy consumption is already considered in the third term of the formulation.

In order to deal with a disaggregated battery, it is necessary to add a new index $v$ for the vehicles to the mathematical formulation (12-22), thus resulting in the following general formulation:

$$
\begin{gathered}
\min \sum_{h}\left(\operatorname{pud}(h) \cdot P E X_{\text {supply }}(h)\right. \\
\left.+\sum_{v}(f o(h, v)-f i(h, v)) P E X_{E V}(h)\right) \\
+\sum_{v}(F(v)+V(v) \cdot C(v))
\end{gathered}
$$

Subject to the following restrictions:

$$
\begin{gathered}
S O C_{\min }(v) \leq S O C(h, v) \leq S O C_{\max }(v) \\
0 \leq i(h, v) \leq C(v) \cdot D R(v) \\
0 \leq o(h, v) \leq C(v) \cdot D R(v) \\
S O C(h, v)=S O C(h-1, v)+i(h, v)-o(h, v) \\
-l(h, v) \\
l(h, v)=S O C(h-1, v) \cdot \Phi_{\text {decay }}(v) \\
f o(h, v)=o(h, v) \cdot \delta_{e f f}(v) \\
i(h, v)=f i(h, v) \cdot \gamma_{e f f}(v) \\
\operatorname{cod}(h, v)=B C T(h, v) \cdot f i(h, v) \\
p v d(h, v)=B C T(h, v) \cdot f o(h, v) \\
\text { pud }(h)=D M D(h, v)+\sum(\operatorname{cod}(h, v)-p v d(h, v)) \\
\text { SOC }(h, v), p u d(h, v), \operatorname{cod}(h, v), p v d(h, v), f i(h, v) \\
f o(h, v), i(h, v), o(h, v) \geq 0
\end{gathered}
$$

It can be noticed that the charging and discharging of each vehicle is treated separately and then grouped in the calculation of the total consumption, pud. Also, in the objective function the fixed and variable costs associated for each vehicle are considered differently as well as the price paid to their owners.

\section{RESULTS}

The optimization algorithm set $\mathrm{C}^{*}$, optimal capacity of the battery, for this application to $100 \mathrm{kWh}$. SOC and net energy demand of the building behaviours are shown in Fig. 4

Depending on initial conditions ( $\mathrm{SOC}(0)$ ), SOC behaviour during the first day remains different than the rest of the days, which show similar charge and discharge pattern regardless of electricity demand of the building. Table 2 shows economical savings depending on PEX_EV: 
TABLE 2. PEX $\mathrm{EV}_{\mathrm{E}}$ and savings.

\begin{tabular}{|c|c|c|c|c|}
\hline & $\mathbf{C}^{*}(\mathbf{k W h})$ & Batt. Cost & Savings (C) & \% \\
\hline 0,03 & 100 & 15100 & 783,27 & 1,60 \\
\hline 0,1 & 100 & 15100 & 202,08 & 0,41 \\
\hline 0,11 & 100 & 15100 & 199,28 & 0,41 \\
\hline
\end{tabular}

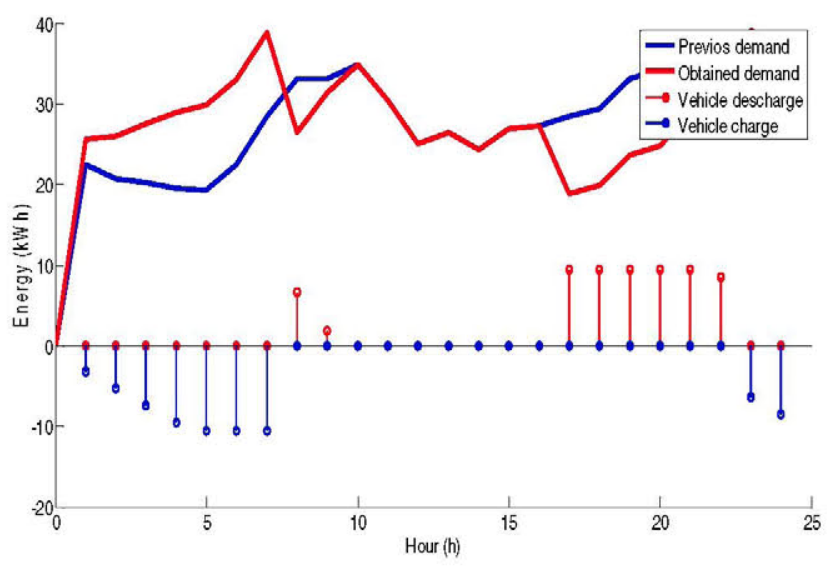

Fig. 5. Original demand and resulting demand with five vehicles.

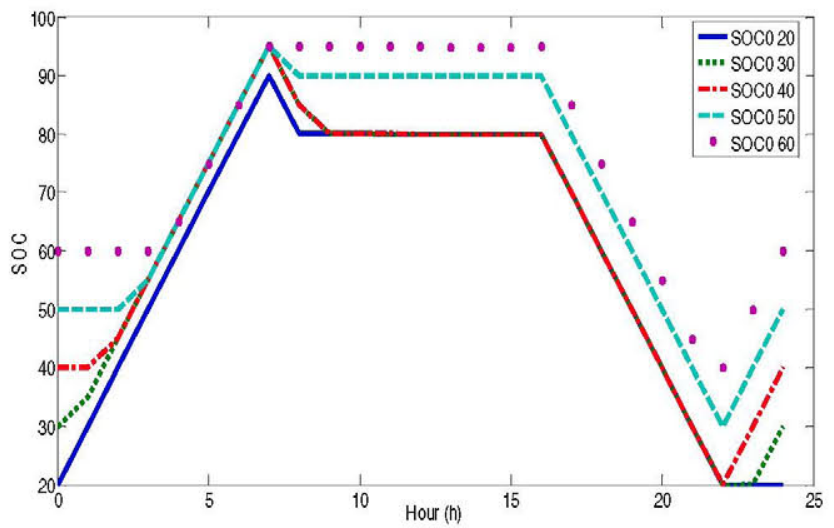

Fig. 6. SOC evolution of each of the five parked vehicles.

It can be seen that the battery costs are too high compared with the annual savings. Therefore, it is more convenient to use EV's batteries instead of static ones.

TABLE 3. Initial SOC and savings.

\begin{tabular}{|c|c|}
\hline INITIAL SOC & SAVINGS (\%) \\
\hline 20 & 0.3921 \\
\hline 30 & 0.4011 \\
\hline 40 & 0.4011 \\
\hline 50 & 0.3810 \\
\hline 60 & 0.3756 \\
\hline
\end{tabular}

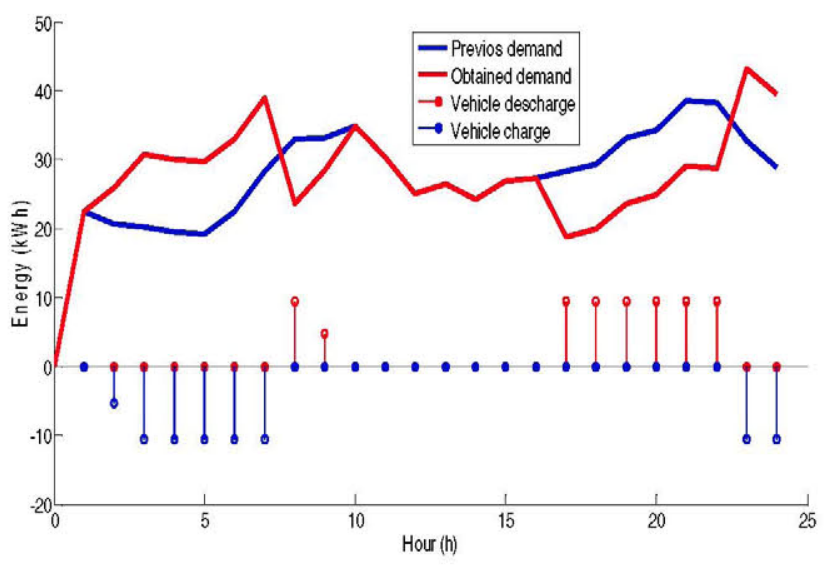

Fig. 7. Equivalent vehicle demand and resulting demand.

Next, the daily operation schedule is analysed. Considering that the optimum capacity is $100 \mathrm{kWh}$, this amount can be divided into five vehicles with $20 \mathrm{kWh}$ capacity each. Fig. 5 shows the variation in demand due to the vehicles' charging schedule for day $05 / 09$.

Table 3 shows the initial SOCs considered for each vehicle and the savings obtained for each of them in percentage of the previous demand's cost. As it can be seen in Fig. 6, depending on the initial SOC a different charge-discharge cycle is applied. Starting with an initial SOC of $30 \%$ and $40 \%$, a full cycle can be applied: charging to the maximum level (95\%), discharging to the minimum $(20 \%)$ and returning to the original SOC. In consequence, the maximum savings can be obtained.

In the case of starting with an initial SOC of $20 \%$, the maximum SOC level cannot be reached in the charge semicycle due to the power limitation in the charging point (with a nominal power of $2 \mathrm{~kW}$, it is not possible to charge as fast as is needed), thus reducing the savings. Similarly, with a higher initial SOC $(50 \%, 60 \%)$, it is not possible to fully discharge the battery. If those limits were to increase, the initial SOC would not need to be considered. Moreover, the savings would increase, since it can be seen that it is a common strategy to partially discharge the battery in the mid-price period instead of the high-price period.

It is also important to highlight that due to the dependency of the battery self-discharging with the SOC, charge is scheduled as late as possible within the low-price period and the discharge occurs as soon as possible.

The results between using five vehicles at the same SOC level (40\%) and one equivalent vehicle with a battery five times higher than the individual ones are compared to verify the previous results. In Fig. 7 and 8 the resulting demand and SOC evolution of the vehicle can be observed, which is equal to the evolution of the vehicle with initial SOC of $40 \%$ from Fig. 6 . The total savings is thus equal to the one that would be obtained with five of the smaller vehicles and higher than the previous selection of vehicles, even though they had the same averaged SOC. 


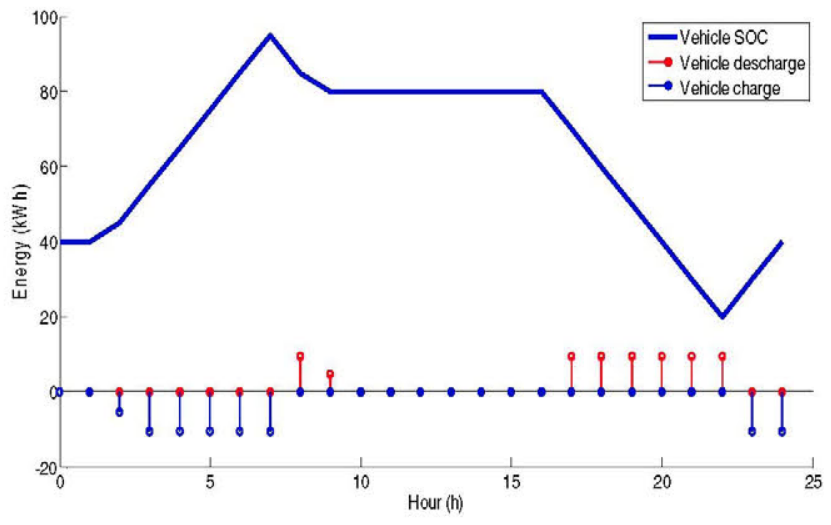

Fig. 8. Equivalent vehicle demand and resulting demand.

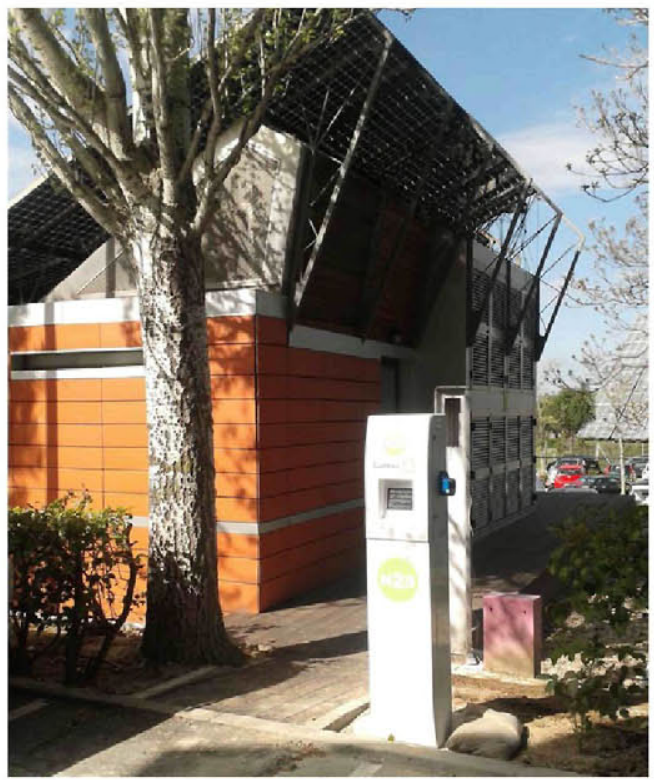

Fig. 9. "Magic Box" pilot plant and charging point installed at UPM.

\section{CONCLUSIONS AND FUTURE WORK}

Considering the daily schedule, it seems to be necessary to establish the vehicle's owner payment according to the initial SOC of the vehicle. Besides, it has been observed that, when using an equivalent vehicle with an average initial SOC, the final benefit may differ due to this dependency.

In the case of requiring a higher final SOC than the initial would be needed at the end of the schedule, this would decrease the margin of benefits, since the deep of discharge would be lower. Also, the price of energy sold should be reconsidered. This system is being implemented in this moment in a real pilot household at E.T.S.I.T. UPM (see Fig. 9).

\section{REFERENCES}

[1] European Parliament and of the Council, Directive 2009/29/EC, Renewable Energy Sources, 23 April 2009. http://ec.europa.eu/clima/policies/package/index en.htm
[2] Eurostat. European Comission "Transport energy consumption and emissions",

http://epp.eurostat.ec.europa.eu/statistics_explained/index.php/Transport energy_consumption_and_emissions

[3] EU transport in Figures. Statistical Pocketbook 2012, http://ec.europa.eu/transport/factsfundings/statistics/doc/2012/pocketbook2012.pdf

[4] International Transport Forum. Reducing transport GHG emissions. Oportunities and Costs. Prelimnary Findings. [Oct. 10, 2013] http://www.internationaltransportforum.org/Pub/pdf/09GHGsum.pdf

[5] United States Environmental Protection Agency. "Sources of Greenhouse Gas Emissions", Sept. 9, 2013 [Oct. 2, 2013] Hhttp://www.epa.gov/climatechange/ghgemissions/sources/transportatio $\underline{\text { n.html }}$

[6] One Million Electric Vehicles by 2015, Department of Energy, USA http://wwwl.eere.energy.gov/vehiclesandfuels/pdfs/1_million_electric_v ehicles rpt.pdf

[7] International Energy http://www.iea.org/aboutus/faqs/energyefficiency/

[8] Europe's Buildings Under Microscope. A country-by-country review of the energy performance of buildings, BPIE, 2011, http://www.europeanclimate.org/documents/LR \%20CbC study.pdf

[9] Energy efficency in Buildings. http://ec.europa.eu/energy/efficiency/buildings/buildings en.htm

[10] http://hes.unwto.org/sites/all/files/docpdf/analysisonenergyusebyeuropea nhotelsonlinesurveyanddeskresearch2382011-1.pdf

[11] http://www.energystar.gov/buildings/sites/default/uploads/tools/SPP\%20 Sales $\% 20$ Flyer $\% 20$ for $\% 20$ Hospitality $\% 20$ and $\% 20$ Hotels.pdf

[12] http://www.fenercom.com/pdf/publicaciones/gestion-energetica-enhoteles-fenercom.pdf

[13] Travel and Tourism Economic Impact 2012. Spain. World Travel and Tourism Council,

[14] Estudio del impacto económico del turismo sobre la economía y el empleo de las Islas Canarias. Impactur 2011.

[15] R. Green, L. Wang, M. Alam "The impact of plug-in hybrid electric vehicles on distribution networks: a review and outlook", Renewable and Sustainable Energy Review, vol, 15, pp. 544-553, 2011.

[16] K. Clement-Nyns, E. Haesen and J. Driesen, "The Impact of Charging Plug-In Hybrid Electric Vehicles on a Residential Distribution Grid", IEEE Trans. On Power Systems, Vol. 25, n. 1, pp. 371-380, Feb. 2010.

[17] C. Camus, C. M. Silva,T. L. Farias and J. Esteves, "Impact of Plug-in Hybrid Electric Vehicles in the Portuguese electric utility system", International Conference on Power Engineering, Energy and Electrical Drives, pp. 285-290, 2009.

[18] E. Sortomme, M. M. Hindi, S. D. J. MacPherson and S. S.Venkata, "Coordinated Charging of Plug-In Hybrid Electric Vehicles to Minimize Distribution System Losses", IEEE Trans. On Smart Grid, Vol. 2, n. 1, pp.198-205, 2011.

[19] G. Haines, A. McGordon and P. Jennings "The Simultaion of Vehicleto-Home Systems - Using Electric Vehicle Battery Storage to Smooth Domestic Electricity Demand", Proc. Of the International Conference and Exhibition on Ecological Vehicles and Renewable Energies. Monaco, 26-29 March 2009.

[20] I. Momber, T. Gómez, G. Venkataramanan, M. Stadler, S. Beer, J. Lai, C. Marnay and V. Battaglia, "Plug-in Electric Vehicle Interactions with a Small Office Building: An Economic Analysis using DER-CAM", http://der.lbl.gov/publications/plug-electric-vehicle-interactions-smalloffice-building-economic-analysis-using-der-cam

[21] M. Stadler, C. Marnay,R. Sharma, G. Mendes, M. Kloess, G. Cardoso, O. Mégel and A. Siddigui, "Modeling Electric Vehicle Benefits Connected to Smart Grids", Proc. of Vehicle Power and Propulsion Conference (VPPC), Chicago (USA), 6-9 September, 2011.

[22] S. Beer, T. Gomez, D. Dallinger, I. Momber, C. Marnay, M. Stadler, J. Lai, "An Economic Analysis of Used Electric Vehicle Batteries Integrated Into Commercial Building Microgrids", IEEE Trans. On Smart Grid, Vol. 3, n 1, pp. 517-525, March 2012.

Gas Natural Fenosa, http://www.gasnaturalfenosa.com/en/1285338501612/home.htm 